\title{
Strength and toughness of clean nanostructured bainite
}

\author{
M. J. Peet ${ }^{\mathrm{a}}$, A. Al-Hamdany ${ }^{\mathrm{a}, \mathrm{c}}$, L. C. D. Fielding ${ }^{\mathrm{a}}$, P. Hill ${ }^{\mathrm{b}}$, M. Rawson ${ }^{\mathrm{b}}$, \\ H.K.D.H. Bhadeshia ${ }^{a}$ \\ ${ }^{a}$ Department of Materials Science and Metallurgy, University of Cambridge, U.K. \\ ${ }^{b}$ Rolls-Royce, Derby, U.K. \\ ${ }^{c}$ University of Technology, Baghdad, Iraq.
}

\begin{abstract}
A nanostructured steel has been produced using a clean steel-making technique. The mechanical properties have been comprehensively characterised. The maximum strength of the material recorded was $2.2 \mathrm{GPa}$ at yield, with an ultimate tensile strength of $2.5 \mathrm{GPa}$, accompanied by a Charpy impact energy of $5 \mathrm{~J}$, achieved by heat treatment to refine the prior austenite grain size from 145 to $20 \mu \mathrm{m}$. This increased strength by $40 \%$ and the Charpy V-notch energy more than doubled.

In terms of resistance of the hardness to tempering, the behaviour observed was similar to previous alloys. Despite reducing the hardness and strength, tempering was observed to reduce the plane-strain fracture toughness.
\end{abstract}

\section{Introduction}

Extremely high strength levels have been achieved in high-carbon steels by transformation to carbide-free bainite at temperatures around $200^{\circ} \mathrm{C}$, with 
the predominant strengthening contribution coming from the high density of interfaces resulting from this low transformation temperature [1-3]. Early work on these nanostructured steels (sometimes referred to as superbainite), which contain a mixture of nanoscaled interlocating bainite plates and retained austenite films, demonstrated excellent combinations of mechanical properties without resort to using expensive alloying, deformation or rapid processing $[1,4-6]$.

Given that superbainitic alloys previously produced by air-melt methods have displayed impressive combinations of properties, there is a strong motivation to explore these steels further in the context of aeroengine components. A difficulty is that at high strength levels there is a sensitivity to flaws such as nonmetallic inclusions, which can reduce the toughness and cause "premature' failure - that is, a smaller fraction of the inherent strength of the microstructure can be realised. For accurate prediction of component service life, detailed knowledge and control of inclusion size and distribution within an alloy is critical - these will have a strong influence on the fatigue life.

Clean steelmaking methods harness vacuum processing to reduce the level of so-called tramp elements (phosphorous and sulphur) and to bring the inclusion size-distribution under control. This is expected to generate improvement in, and perhaps more importantly reduce variability of, mechanical 


\begin{tabular}{lcccccccccccc}
\hline & $\mathrm{C}$ & $\mathrm{Si}$ & $\mathrm{Mn}$ & $\mathrm{Mo}$ & $\mathrm{Cr}$ & $\mathrm{V}$ & $\mathrm{Ni}$ & $\mathrm{Co}$ & $\mathrm{P}$ & $\mathrm{S}$ & $\mathrm{N}$ & $\mathrm{O}$ \\
\hline VIM & 0.99 & 1.43 & 1.89 & 0.26 & 1.28 & 0.09 & 0.04 & 1.50 & $<0.005$ & 0.0018 & & \\
VAR & 0.97 & 1.43 & 1.59 & 0.26 & 1.28 & 0.09 & 0.04 & 1.51 & $<0.005$ & 0.0012 & 0.002 & 0.024 \\
\hline Alloy-V & 0.98 & 1.46 & 1.89 & 0.26 & 1.26 & 0.09 & - & - & $<0.002$ & $<0.002$ & 0.003 & 0.027 \\
Alloy-Co & 0.80 & 1.59 & 2.01 & 0.24 & 1.00 & - & - & 1.51 & $<0.002$ & $<0.002$ & 0.003 & 0.013 \\
\hline
\end{tabular}

Table 1: Chemical composition of alloy, wt\%, following vacuum induction melting (VIM) and vacuum arc remelting (VAR) and comparison to air-melted superbainitic alloys, wt\%. Details of Alloy-V [2, 7] and Alloy-Co [8] have been previously reported. Oxygen and nitrogen determination in this work using LECO combustion analysis, with oxygen by infrared absorption and nitrogen by thermal conductivity.

properties. In this work, a new, 'clean', nanostructured bainitic steel has been characterised and its mechanical properties measured, with the aim of assessing its suitability for future aerospace applications. Particular attention is paid to the effects of tempering, in order to understand how this new alloy responds to the thermal conditions typically associated with aeroengine operation.

\section{Experimental Details}

A bar of the steel was produced using vacuum induction melting (VIM) followed by vacuum arc remelting (VAR). These processes comprise a standard production route for aerospace components. The compositions after each step are shown in Table 1. This composition is close to previously developed nanostructured steel $[2,7,8]$. The use of $\sim 0.1 \mathrm{wt} \%$ vanadium is intended to refine the austenite grain size, and cobalt additions to accelerate the transformation. Since the alloy has been produced by clean steel-making methods, levels of sulphur, nitrogen and oxygen were expected to be lower than in the 
air melted alloys previously described by Garcia-Mateo et al. [2, 7, 8]. As can be seen in Table 1 sulphur and nitrogen content was sucessfully decreased, however the oxygen content was between the levels seen in the two air-melted alloys.

The sulphur content was lowered as a result of the vacuum arc remelting process. Removal of sulphur limits the quantity of sulphide inclusions formed, and hence can improve mechanical properties. Depending on the strength, toughness and distribution of sulphides within an alloy, the effect of sulphides can be related to the mechanical properties via the length of inclusions, the inclusion spacing, the volume fraction of particles, and the weight fraction of sulphur.

After casting an ingot $20.3 \mathrm{~cm}$ in diameter the material was homogenised at $1200^{\circ} \mathrm{C}$ for 2 days. Forging took place at $1040^{\circ} \mathrm{C}$ to produce a bar measuring $8.9 \mathrm{~cm} \times 12.7 \mathrm{~cm}$. After forging, the material was furnace cooled to room temperature. Cross sections from the bar were supplied in both forged and forged-and-annealed conditions for characterisation of the microstructure. Annealing took place at a temperature of $790^{\circ} \mathrm{C}$ for $1 \mathrm{~h}$ followed by furnace cooling.

Following metallographic examination, the bars were transformed to a bainitic condition via austenitisation at $1000^{\circ} \mathrm{C}$ for $40 \mathrm{~min}$, followed by isothermal 


\begin{tabular}{lc}
\hline Temperature $/{ }^{\circ} \mathrm{C}$ & Time \\
\hline 300 & $6 \mathrm{~h}$ \\
400 & $2,6,8 \mathrm{~h}$ \\
400 & $50,100,150,200,250,300 \mathrm{~min}$ \\
450 & $6 \mathrm{~h}$ \\
500 & $6 \mathrm{~h}$ \\
600 & $6 \mathrm{~h}$ \\
\hline
\end{tabular}

Table 2: Tempering treatments applied to the mechanical test samples. Note that the alloy was tempered for several different lengths of time at $400^{\circ} \mathrm{C}$.

transformation in a salt bath at $250^{\circ} \mathrm{C}$ for $40 \mathrm{~h}$. A second set of samples was austenitised at $1000^{\circ} \mathrm{C}$ for $1 \mathrm{~h}$ followed by isothermal transformation at $200^{\circ} \mathrm{C}$ for 9 days, for the purpose of mechanical testing in the high hardness condition. In an attempt to further control the grain size, an alternative set of austenitisation conditions $\left(885^{\circ} \mathrm{C}\right.$ for $\left.30 \mathrm{~min}\right)$ was also used. In all cases, the samples were oil-quenched to room temperature when the isothermal treatment was complete. Bainitic samples were further tempered under a range of conditions in order to examine the influence of tempering on the mechanical properties. A complete list of the tempering treatments used is provided in Table 2.

\section{Metallography}

Metallographic observations were conducted using optical, scanning electron and transmission electron microscopy. Except where specified, metallography was carried out on the forged-and-annealed bar of material in the as-received 
and as-transformed conditions. Samples were taken from the outer edge of the bars, before transforming to bainite, and were metallographically polished. Imaging and electron dispersive spectroscopy (EDS) were performed using a Camscan MX2600 FEGSEM scanning electron microscope. A JEOL 200CX transmission electron microscope was used to characterise the nanostructure in greater detail.

\section{Grain size measurement}

The thermal etching technique described by Andrés et al. was used to measure the austenite grain size [9]. In order to generate the thermal etch, flat surfaces were ground and polished on cylinders measuring $8 \mathrm{~mm}$ in diameter and $12 \mathrm{~mm}$ in length, machined from the forged bar. These were austenitised by various heat treatments and then rapidly cooled to room temperature. Micrographs of the flat surfaces were taken, and the differential interference technique was used to enhance the contrast caused by the grain boundary surface relief. These boundaries were manually highlighted using graphics processing software and the number of grains counted. Grain size was also measured using the linear intercept method [10]. This generated two estimates of grain size: $\sqrt{A / n}$, which is the total area divided by the number of grains; and $\bar{L}$, which is the mean linear intercept. All measurements were made on material taken from the forged-and-annealed bar. 
Thermodynamic calculations

All thermodynamic calculations were performed using MTDATA 4.73, with updated sgte_sol database (plus).

\section{Mechanical Testing}

Except where stated otherwise, all mechanical testing was conducted on forged samples austenitised at $1000^{\circ} \mathrm{C}$ and transformed to bainite at $200^{\circ} \mathrm{C}$ for 9 days.

Two sets of tensile specimens were manufactured: one for measurements to be made on tempered specimens, and the second for measurements made on as-transformed specimens (in order to study the effect of austenite grain size). The as-transformed specimens were produced with a gauge length of $25.3 \mathrm{~mm}$ and $5 \mathrm{~mm}$ circular cross section.

Fracture toughness test specimens were produced according to the geometry in Figure 1(a). The samples were heat-treated as blanks prior to final machining of the surface and notch. Plane strain fracture toughness tests were conducted according to the ASTM E399-90 standard [11]. All tests were conducted in laboratory air at room temperature. Each sample was fatigue pre-cracked using a step-down loading method incorporating a sine wave load of frequency $50 \mathrm{~Hz}$. The toughness test was then performed using a loading rate of $1 \mathrm{~mm} \mathrm{~min}^{-1}$. 
Fatigue crack growth rate was also measured, using samples of the shape and dimensions shown in Figure 1(b). Testing was conducted according to the ASTM E647 standard, on a Mayes 100 kN Servo Hydraulic machine using a sinusoidal waveform with a frequency of $10 \mathrm{~Hz}$. The ratio of minimum to maximum stress $R_{\sigma}$ was 0.2 .

An indenter load of $30 \mathrm{~kg}$ was used to make Vickers hardness measurements on all samples.

Low cycle fatigue testing at $0.25 \mathrm{~Hz}$ used a trapezoidal 1-1-1-1 profile, $1 \mathrm{~s}$ hold at minimum stress, linearly ramp for $1 \mathrm{~s}$, hold at maximum stress for $1 \mathrm{~s}$, before ramping back down to the minimum. After heat treatment, blanks were machined to the final dimensions for testing $4.5 \mathrm{~mm}$ diameter $12 \mathrm{~mm}$ gauge length with a radius $9 \mathrm{~mm}$ between the gauge length and the $20 \mathrm{UNF}$ threads. The gauge length was polished longitudinally to give a $0.25 \mu \mathrm{m}$ finish.

Air-melted alloys

The chemical compositions of two air-melted superbainitic alloys are provided in Table 1. These are typical nanostructured bainitic steels, which have 


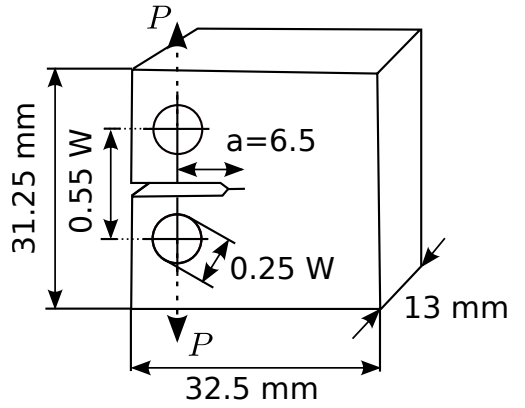

(a) $\mathrm{K}_{\mathrm{IC}}$ sample

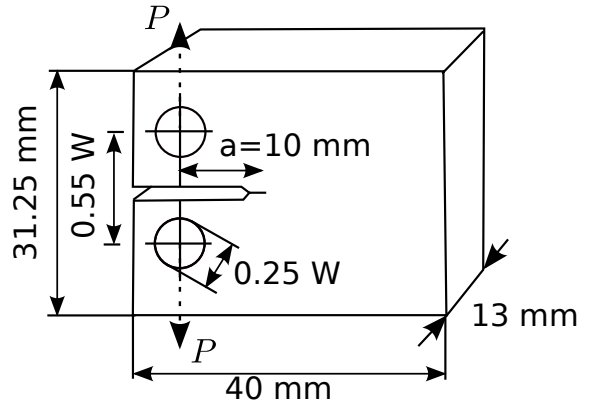

(b) Crack growth rate sample

Figure 1: Dimensions of plane-strain fracture toughness $\left(\mathrm{K}_{\mathrm{IC}}\right)$ and crack growth rate test specimens.

been reported upon extensively $[2,7,8,12]$. Details of the alloy design and manufacture can be found in the original work $[7,8]$. These alloys have been selected for comparison with the clean alloy studied in this work, due to the similarities in composition and heat treatment required to produce them.

\section{Results and Discussion}

\section{Metallography}

An interesting unexpected observation is the corrosion caused by transformation in the salt bath, figure 2. The exposure time during the low-temperature bainite transformation is much longer than for transformation of conventional steels, although the possibility exists that the corrosion initiated at cracks formed initially on quenching. EDS analysis showed ingress of material with high chlorine and oxygen levels, limited to the outer $1 \mathrm{~mm}$ of the Charpy blanks and was removed by final machining. 


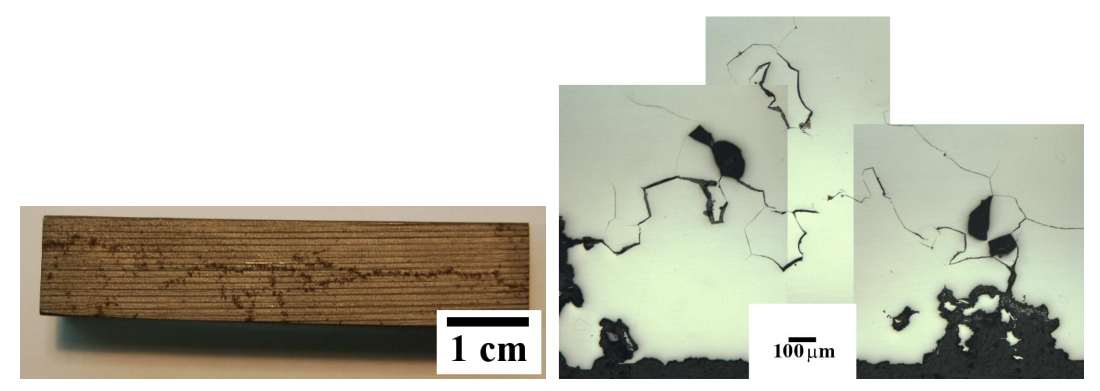

Figure 2: Corrosion caused by exposure to salt bath environment during isothermal transformation.

Optical microscopy and EDS analysis of the as-received VIM/VAR processed bars revealed the presence of manganese sulphide inclusions measuring up to $10 \mu \mathrm{m}$ in size. These preliminary results initiated further experiments to characterise the inclusions, using samples taken from the centre of the ingot, in directions normal and perpendicular to the forging.

Samples from the outer edge of the bar revealed the MnS inclusions as circular particles in the cross-section perpendicular to the length of the forging. Similar inclusions were seen during optical examination of samples taken from the centre of the bar. In this case, the inclusions take the form of stringers running in the direction of forging. It was also found that many of the MnS inclusions were associated with areas rich in zirconium, which is only expected to be present in trace amounts in the steel. 


\begin{tabular}{lcc}
\hline Material & As-received hardness / HV & Bainitic hardness / HV \\
\hline Forged & $360 \pm 4$ & $619 \pm 7$ \\
Forged and annealed & $343 \pm 5$ & $616 \pm 10$ \\
\hline
\end{tabular}

Table 3: Vickers hardness measured before and after bainite transformation in VIM-VAR processed alloy.

SEM observations indicated that the pearlitic structure of the forged material became spherodised following annealing. The pearlitic structure can be seen around the inclusions after polishing, which suggests that some preferential polishing has occurred. In particular, it was noted that the lamellar spacing is larger near the inclusions, probably owing to pearlite nucleating there at a higher temperature during the cooling process.

Optically, the structure of the bars following isothermal heat treatment consists of sheaves or packets of carbide-free bainite, with small areas of 'blocky' retained austenite measuring $\sim 2 \mu \mathrm{m}$ in size. Transmission electron micrographs also revealed the presence of thin films of retained austenite separating individual ferrite plates, as is expected. Table 3 shows the change in hardness that occurs due to bainitic transformation.

The measured austenite grain sizes are reported in Table 4. Included for comparison are measurements taken from Alloy-V and Alloy-Co. The grain size of the new alloy following austenitisation at $1000^{\circ} \mathrm{C}$ for $1 \mathrm{~h}$ was similar to 


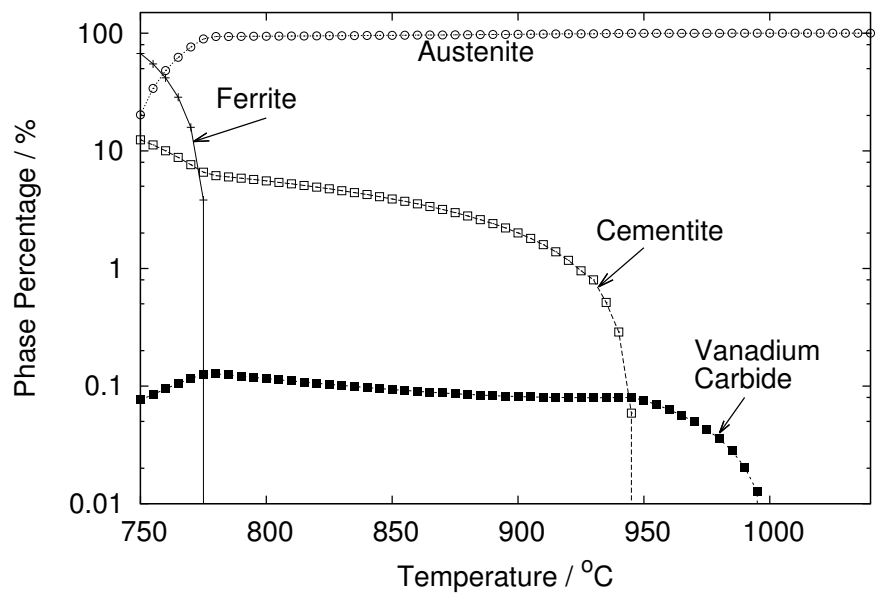

Figure 3: Equilibrium phase diagram for VAR alloy calculated using MTDATA.

that of Alloy-Co, but much larger than that of Alloy- $\mathrm{V}$. This is reasonable, owing to the increased cleanliness of the new steel. As shown in Figure 3 thermodynamic calculations using MTDATA indicated that cementite is an equilibrium phase below $930^{\circ} \mathrm{C}$ in the current alloy, while vanadium carbide is present at temperatures below $1020^{\circ} \mathrm{C}$. After austenitisation at $1000^{\circ} \mathrm{C}$ the prior austenite grain size was much larger than after heat treatment at $900^{\circ} \mathrm{C}$, which is thought to explain the improvement in mechanical properties. The change of cooling rate by the use of oil quenching rather than quenching into a salt bath is not expected to greatly influence the resulting microstructure in this alloy, based on calculated transformation kinetics and dilatometry experiments. 
Refinement of the austenite grain size is thought to be desirable for improvement of the toughness, by reducing the bainite sheaf size [13]. However, austenitisation at a lower temperature leads to retention of carbide particles in the final microstructure, the size and distribution of which will have an effect on the final mechanical properties. Carbides forming along prior austenite grain boundaries are likely to reduce toughness, whereas if they can be distributed as spherical particles they are more likely to prevent grain growth and be less deleterious to the toughness. As can be seen in figure 4 in the Charpy toughness test, there is evidence of intergranular fracture along the prior austenite grains.

Transmission electron microscopy confirmed that the expected nanostructure can be achieved in this material without any particular resort to accelerated cooling. The structure of fine plates of ferrite separated by thin films of retained austenite after transformation at $250^{\circ} \mathrm{C}$ can be seen in figure 5 . At lower magnification we can observe that this structure makes up most of the microstructure, very fine areas of blocky retained austenite are also observed, having size less than around $2 \mu \mathrm{m}$, figure 6 . 


\begin{tabular}{lcccc}
\hline Conditions & $\bar{L} / \mu \mathrm{m}$ & $\sqrt{A / n} / \mu \mathrm{m}$ & Alloy $\mathrm{V} \bar{L} / \mu \mathrm{m}$ & Alloy Co $\bar{L} / \mu \mathrm{m}$ \\
\hline $885^{\circ} \mathrm{C} \mathrm{30} \mathrm{min}$ & $20.4 \pm 1.1$ & - & - & - \\
$900^{\circ} \mathrm{C} 30 \mathrm{~min}$ & $18.7 \pm 0.4$ & 20.2 & - & $29 \pm 2$ \\
$1000^{\circ} \mathrm{C} 15 \mathrm{~min}$ & $85.0 \pm 2.5$ & 98 & $49 \pm 2$ & $88 \pm 4$ \\
$1000^{\circ} \mathrm{C} 40 \mathrm{~min}$ & $99.0 \pm 4$ & 126 & - & - \\
$1000^{\circ} \mathrm{C} 1 \mathrm{~h}$ & $145 \pm 10$ & - & - & - \\
$1040^{\circ} \mathrm{C} 15 \mathrm{~min}$ & $156 \pm 3$ & 180 & - & - \\
\hline
\end{tabular}

Table 4: Measured mean linear intercept $(\bar{L})$ austenite grain sizes after austenitisation of VIM-VAR processed alloy. Included for comparison are grain sizes measured in Alloy-V [2] and Alloy-Co [8]. The error reported is equal to one standard deviation of the distribution.

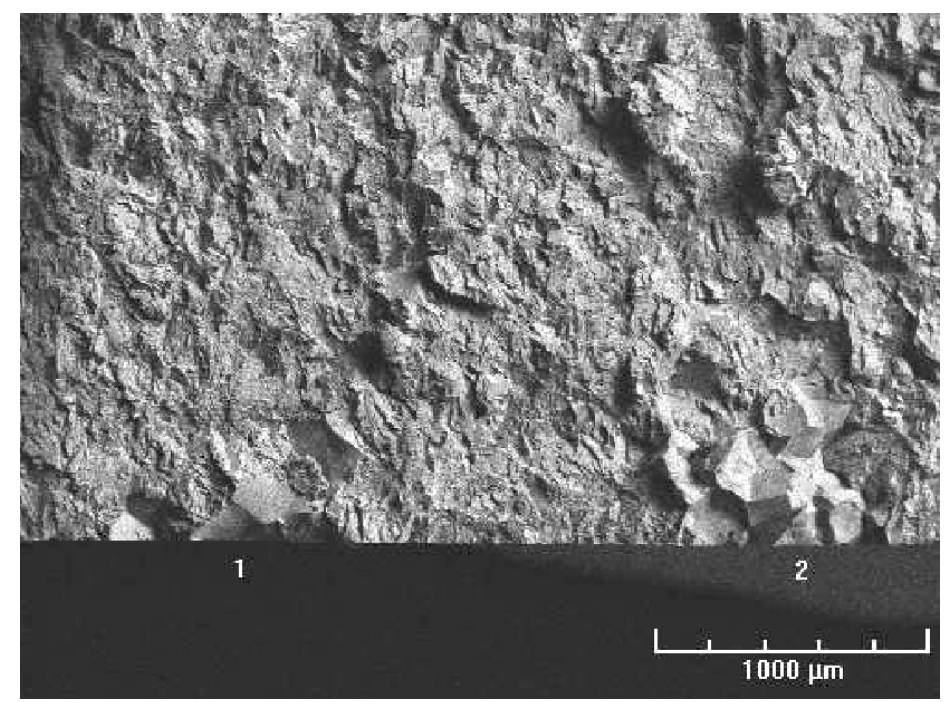

Figure 4: Fracture surface of Charpy test specimen after transformation at $200^{\circ} \mathrm{C}$, intergranular fracture can be seen at 1 and 2 . 


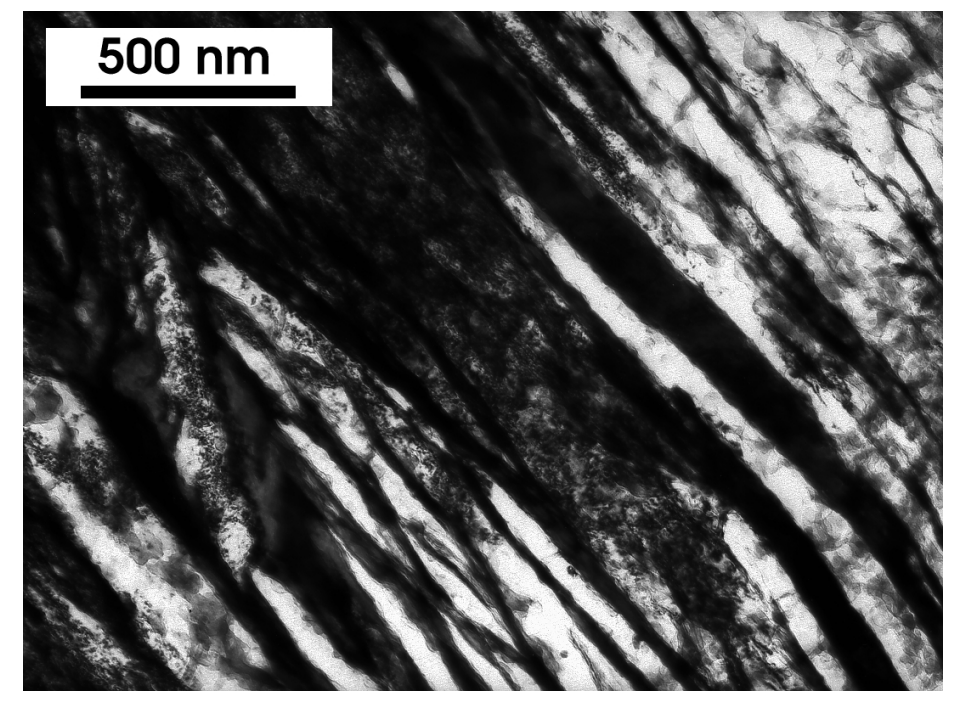

Figure 5: Bainite nanostructure achieved after isothermal transformation at $250^{\circ} \mathrm{C}$, austenitisation at $1000^{\circ} \mathrm{C}$ for $40 \mathrm{~min}$, followed by transformation at $250^{\circ} \mathrm{C}$ for $40 \mathrm{~h}$. Light regions correspond to ferrite plates, which have also been preferentially etched, darker regions here are retained austenite.

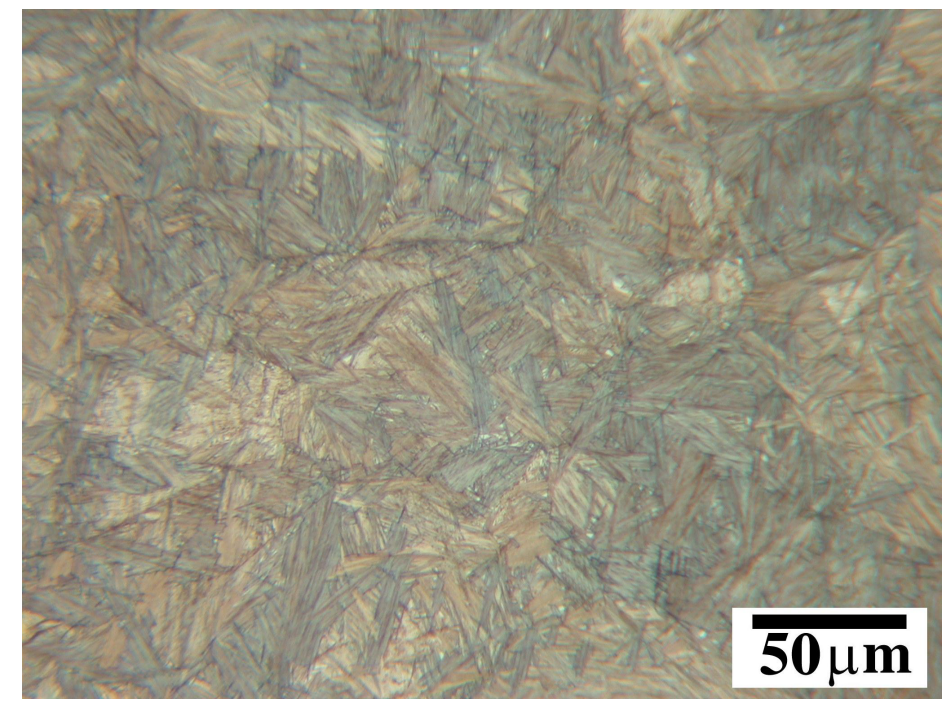

Figure 6: Bainite formed isothermally at $250^{\circ} \mathrm{C}$ for $40 \mathrm{~h}$, only a very small amount of 'blocky' retained austenite (white) is present in the microstructure. 


\begin{tabular}{llccccc}
\hline $\bar{L} / \mu \mathrm{m}$ & Position & $\begin{array}{c}\text { Hardness } \\
/ \mathrm{HV}\end{array}$ & $\begin{array}{c}\sigma_{0.2 \mathrm{YS}} \\
/ \mathrm{MPa}\end{array}$ & $\begin{array}{c}\sigma_{\mathrm{UTS}} \\
/ \mathrm{MPa}\end{array}$ & $\begin{array}{c}\text { Impact } \\
\text { energy } / \mathrm{J}\end{array}$ & $\begin{array}{c}K_{Q} \\
/ \mathrm{MPam}^{\frac{1}{2}}\end{array}$ \\
\hline \multirow{2}{*}{145} & $\mathrm{~L}$ & 649 & 1383 & 1622 & $2.3 \pm 0.2$ & $\mathbf{3 0 . 0}\left(K_{1 \mathrm{C}}\right)$ \\
& $\mathrm{T}$ & 649 & $1571 \pm 34$ & $1773 \pm 47$ & $2.4 \pm 0.1$ & $32.3\left(K_{Q}\right)$ \\
20 & $\mathrm{~L}$ & 684 & $2199 \pm 8$ & $2517 \pm 2$ & 4.6 & - \\
& $\mathrm{T}$ & 684 & $2198 \pm 7$ & $2521 \pm 10$ & $4.6 \pm 0.1$ & - \\
\hline
\end{tabular}

Table 5: Influence of sample orientation ( $\mathrm{L}$ - longitudinal and $\mathrm{T}$ - transverse) and austenite grain size on the mechanical properties of the as-transformed alloy. Bold type indicates where the stress intensity at failure $K_{Q}$ can be accepted as the plane strain fracture toughness $K_{1 \mathrm{C}}$. Errors, where known, are presented as one standard deviation of the distribution of results.

Effect of prior austenite grain size

Our results demonstrate that refinement of the prior austenite grain size can lead to improved mechanical properties for the clean superbainitic steel.

Table 5 shows the mechanical test results taken from four sets of samples, all transformed to bainite at $200^{\circ} \mathrm{C}$ for 9 days. The austenitisation treatment was varied $\left(1000^{\circ} \mathrm{C}\right.$ for $1 \mathrm{~h}$ vs. $885^{\circ} \mathrm{C}$ for $\left.30 \mathrm{~min}\right)$ in order to alter the austenite grain size. The influence of sample orientation was also investigated, with specimens being machined in the transverse and longitudinal directions (taken relative to the rolling direction). Whether this has a significant effect is not clear from the data, however. Elongation was not possible to measure reliably since in all tensile tests the specimen failed in the threaded portion.

Generally nanostructured bainite, in comparison to other steels, is found to exhibit poor Charpy impact energy, but reasonable $K_{1 C}$ fracture toughness $[6,14]$. This same trend is observed with the current steel. Although 
no valid $K_{I C}$ fracture toughness results were obtained for the sample with $\bar{L}=20 \mu \mathrm{m}$, it can be seen (table 5 ) that the impact toughness has doubled with a reduction in austenite grain size. Pleasingly, the tensile properties also improved markedly, reaching yield strength values in excess of $2 \mathrm{GPa}$ and ultimate strength of $2.5 \mathrm{GPa}$.

Reducing the prior austenite grain size in this work resulted in increase in hardness. Conversly, Garcia-Mateo et al. found that the hardness of AlloyCo fell after austenitisation at $900^{\circ} \mathrm{C}$ instead of $1000^{\circ} \mathrm{C}$, despite the fact that the former treatment both decreased the bainite plate thickness and enhanced the transformation kinetics, producing a greater final volume fraction of bainite [7]. The data presented in Table 5 are in line with the expected effects of the microstructural changes observed above.

Meanwhile, the hardness of Alloy-V (619 HV20) is significantly lower than that of Alloy-Co (690 HV20), possibly due to a reduced volume fraction of bainite [7]. It is noted that the influence of austenite grain size upon transformation kinetics can be either positive or negative, depending on whether nucleation or growth dominates the overall transformation rate [15-17].

The mechanical properties achieved in the current clean alloy compare favourably with those obtained in previous superbainitic steels. The improvement in toughness-strength combinations, achieved via reduction of austenite grain 
size, is impressive. A similar steel developed by Avishan et al. was reported to have an ultimate tensile strength of $2.1 \mathrm{GPa}$ and impact energy of $10 \mathrm{~J}$ at room temperature [18].

\section{Low Cycle Fatigue}

The uniaxial fatigue life at $20^{\circ} \mathrm{C}$ and $300^{\circ} \mathrm{C}$ is shown in figure 7 . The fatigue life is longer at the higher testing temperature. The fatigue properties at room temperature are poor in comparison to those previously reported for an air-melted composition of super-bainite [19]. Possibly due to the large prior austenite grain size and the poor elongation (neglibible plastic deformation was observed in the tensile tests) exhibited for this heat treatment condition. The improvement in fatigue properties at $300^{\circ} \mathrm{C}$ is of interest for applications at elevated temperatures.

\section{Tempering}

Exposure to thermal transients can take place either in service or to apply surface coatings in the range $350-490^{\circ} \mathrm{C}$, depending on whether further treatments are applied to the material such as nitriding, or the addition of sacrificial paint. Understanding the thermal stability of candidate alloys is therefore important. The tempering behaviour of nanostructured bainite has been reported on previously [12, 20-23] and the tempering response of the 


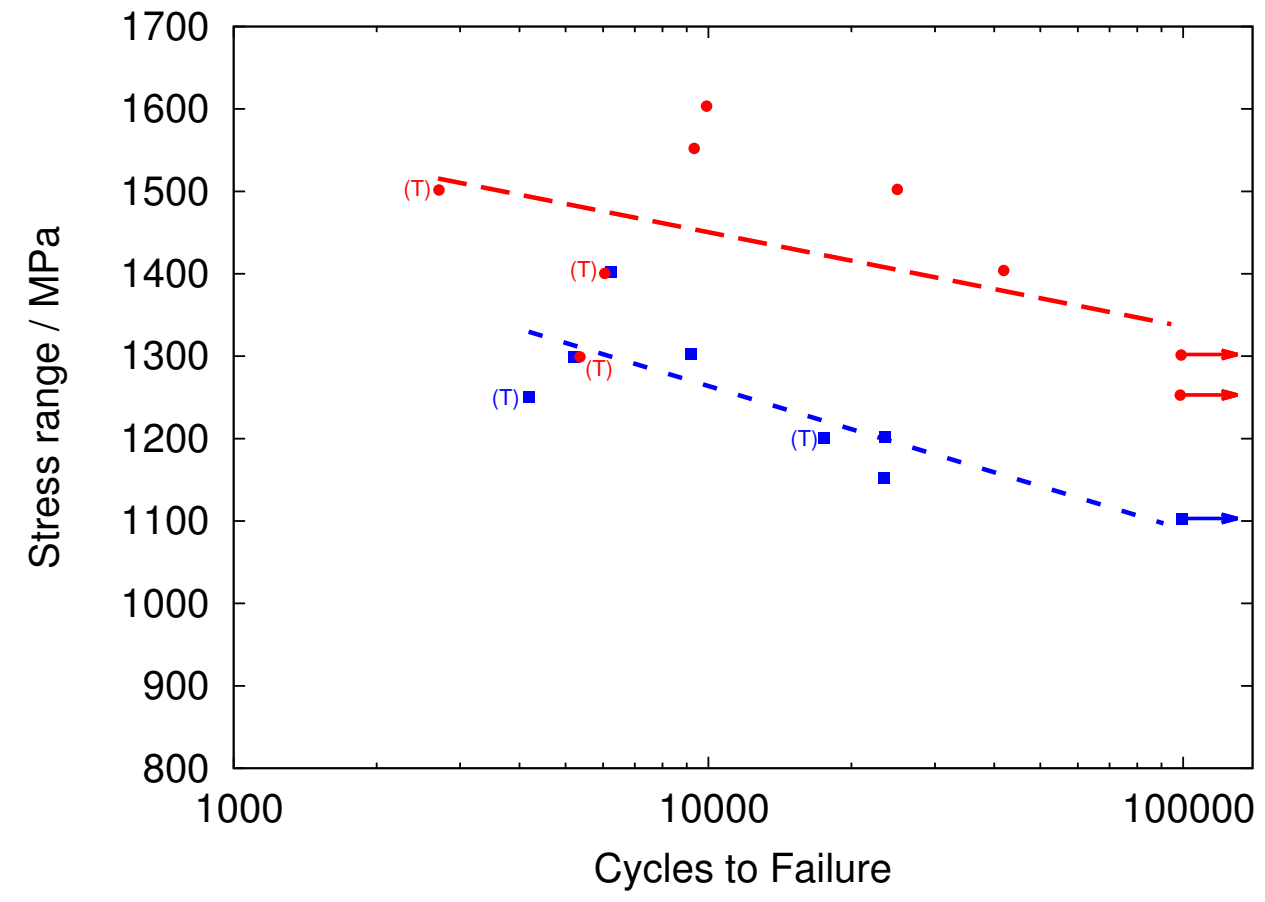

Figure 7: Stress and number of cycles to failure (S-N curve) for low cycle fatigue life, with stress ratio $\mathrm{R}=0$, frequency $0.25 \mathrm{~Hz}$, at $20^{\circ} \mathrm{C}$ and $300^{\circ} \mathrm{C}$ after $1 \mathrm{~h}$ austenitisation at $1000^{\circ} \mathrm{C}$ and $10 \mathrm{~d}$ transformation at $200^{\circ} \mathrm{C}$. ( T) indicates that the sample was from the transverse direction. Testing was stopped after 100,000 cycles. 


\begin{tabular}{lccc}
\hline Sample condition & $V_{\gamma} / \mathrm{vol} \%$ & $V_{\alpha_{\mathrm{b}}} / \mathrm{vol} \%$ & $C_{\gamma} / \mathrm{wt} \%$ \\
\hline As-transformed & $32.1 \pm 0.11$ & $67.9 \pm 0.73$ & $1.37 \pm 0.01$ \\
Tempered at $400^{\circ} \mathrm{C}$ for $6 \mathrm{~h}$ & $15.5 \pm 0.40$ & $84.5 \pm 0.40$ & $0.79 \pm 0.01$ \\
Tempered at $450^{\circ} \mathrm{C}$ for $6 \mathrm{~h}$ & $4.5 \pm 0.55$ & $95.5 \pm 0.55$ & $0.53 \pm 0.17$ \\
\hline
\end{tabular}

Table 6: Percentage by volume of austenite $\left(V_{\gamma}\right)$ and bainitic ferrite $\left(V_{\alpha_{\mathrm{b}}}\right)$, and carbon content of austenite $\left(C_{\gamma}\right)$ measured using X-ray diffraction.

current alloy, after transformation at $200^{\circ} \mathrm{C}$, is investigated here.

Figures 8-9 show the reduction in hardness due to tempering at various temperatures and times. Comparisons are also made with a similar bainitic alloy, denoted Alloy A with composition Fe-0.79C-1.59Si-1.94Mn-0.02Ni-1.33Cr$0.3 \mathrm{Mowt} \%$ [12]. It is evident that the overall reduction in hardness due to tempering is limited at temperatures of $500^{\circ} \mathrm{C}$ and below. It has been shown previously that nanostructured bainite is resistant to tempering due to the precipitation of carbide particles at the ferrite plate interfaces [12, 20, 23]. This restricts coarsening of the structure, preserving the hardness. Alloy A — also a superbainitic steel — shows similar behaviour.

Table 6 shows the change in phase fractions and austenite lattice parameter as a result of tempering for $6 \mathrm{~h}$ at $400^{\circ} \mathrm{C}$ and $450^{\circ} \mathrm{C}$. The austenite content decreases appreciably as a result of thermal decomposition into cementite and ferrite; however, it is possible that some austenite is retained but transformed to untempered martensite when cooled to room temperature after 


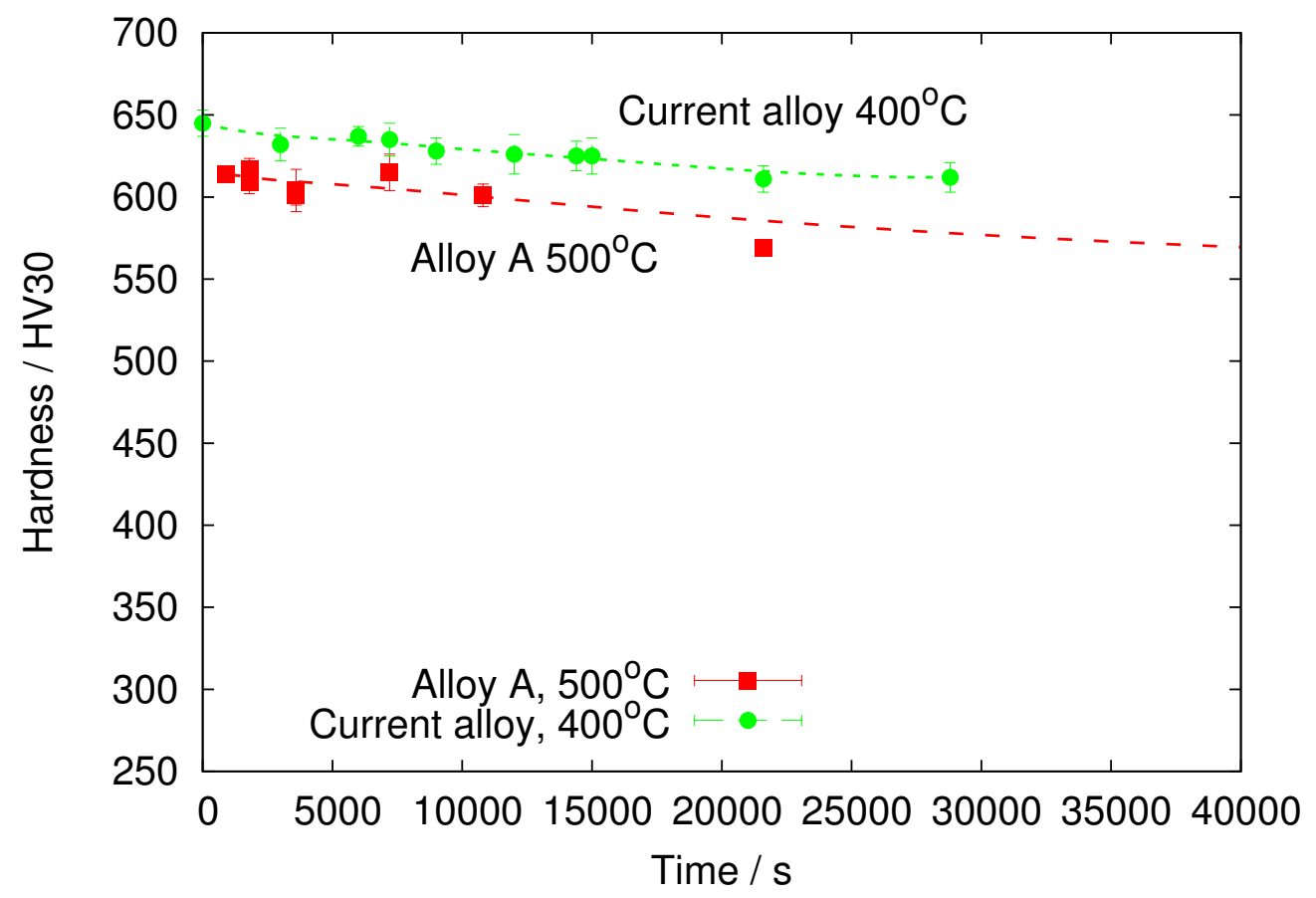

Figure 8: Hardness development during tempering at various temperatures. 


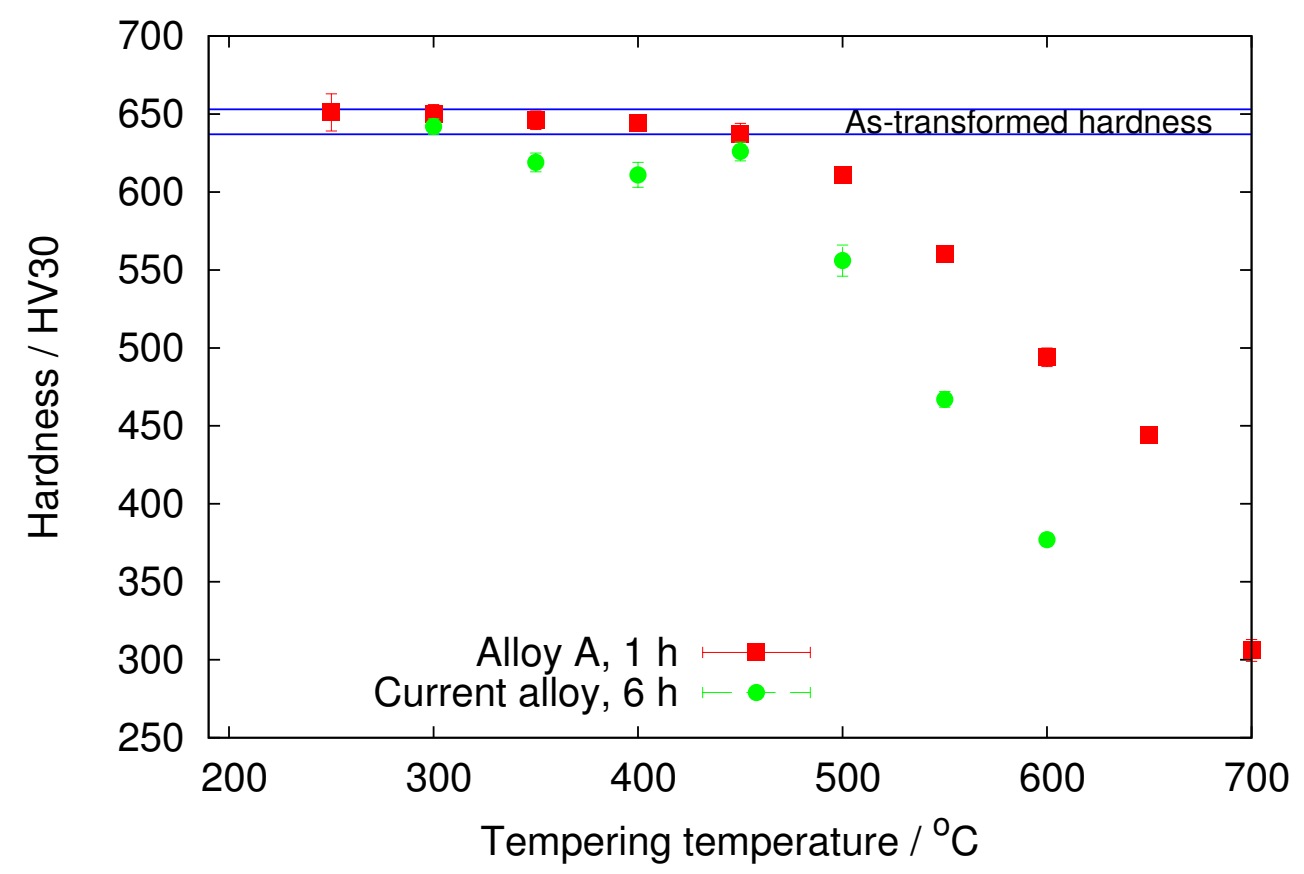

Figure 9: Hardness of alloy after $6 \mathrm{~h}$ tempering at various temperatures. 
tempering $[14,24]$. It is speculated that a small amount of austenite will still be present in the structure when the tempering temperature remains below $500^{\circ} \mathrm{C}$, but will completely decompose just below $550^{\circ} \mathrm{C}$ when tempering for times less than $1 \mathrm{~h}$. The decomposition of austenite results in a small increase in the bainite plate thickness, as described previously [12]. A large drop in hardness finally occurs only when carbide and grain boundary coarsening occurs.

Tensile tests were performed on samples that had undergone various tempering treatments; the results are set out in Table 7 . The yield strength and tensile strength of the alloy in the isothermally transformed condition were $1383 \mathrm{MPa}$ and $1622 \mathrm{MPa}$, respectively. There is a limited loss of strength that occurs due to tempering at temperatures as high as $600^{\circ} \mathrm{C}$, since the primary contribution to strength in this alloy is the extremely fine bainitic plate thickness $[12,20]$. Due to the low elongation in the as-transformed condition, loss of hardness due to tempering results in higher tensile strength being achieved.

Table 8 lists the $K_{Q}$ values for various tempering conditions. The general trend is that of a decrease in fracture toughness as tempering temperature increases. This is due to the loss of the tougher retained austenite phase, which is replaced by ferrite and brittle carbides [23]. In some cases, untempered martensite can form from carbon depleted retained austenite during cooling [25]. 


\begin{tabular}{lcc}
\hline Sample condition & $\sigma_{0.2 \mathrm{YS}} / \mathrm{MPa}$ & $\sigma_{\mathrm{UTS}} / \mathrm{MPa}$ \\
\hline As-transformed & 1383 & 1622 \\
Tempered at $300^{\circ} \mathrm{C}$ for $6 \mathrm{~h}$ & 1285 & 1285 \\
Tempered at $400^{\circ} \mathrm{C}$ for $8 \mathrm{~h}$ & 950 & 968 \\
Tempered at $450^{\circ} \mathrm{C}$ for $6 \mathrm{~h}$ & 1253 & 1289 \\
Tempered at $600^{\circ} \mathrm{C}$ for $6 \mathrm{~h}$ & 1267 & 1514 \\
\hline
\end{tabular}

Table 7: Ultimate tensile strength $\left(\sigma_{\mathrm{UTS}}\right)$ and $0.2 \%$ yield strength $\left(\sigma_{0.2 \mathrm{YS}}\right)$ measured in bainitic samples tempered under various conditions. The sample tempered at $400^{\circ} \mathrm{C}$ is thought to be an anamalously low value, possibly due to the presence of defects or inclusions in the sample, although no feature was clearly identified. A large scatter in the results can be expected from the low ductility in these conditions.

\begin{tabular}{lc}
\hline Sample condition & $K_{Q} / \mathrm{MPam}^{\frac{1}{2}}$ \\
\hline As-transformed & 31 \\
Tempered at $300^{\circ} \mathrm{C}$ for $6 \mathrm{~h}$ & 27 \\
Tempered at $300^{\circ} \mathrm{C}$ for 1 month & 23 \\
Tempered at $\mathbf{4 0 0} \mathbf{C}$ for $\mathbf{8 ~ h}$ & $\mathbf{2 3}\left(K_{1 \mathrm{C}}\right)$ \\
Tempered at $450^{\circ} \mathrm{C}$ for $6 \mathrm{~h}$ & 20 \\
Tempered at $\mathbf{5 0 0} \mathbf{C}$ for $\mathbf{6 ~ h}$ & $\mathbf{2 2}\left(K_{1 \mathrm{C}}\right)$ \\
Tempered at $600^{\circ} \mathrm{C}$ for $6 \mathrm{~h}$ & 14 \\
\hline
\end{tabular}

Table 8: Fracture toughness $\left(K_{Q}\right)$ measured in bainitic samples tempered under various conditions. The rows in bold type indicate where the test satisfied the conditions such that $K_{Q}=K_{1 \mathrm{C}}$.

Fatigue crack growth rate

The fatigue crack growth rate results are presented in Figure 10. It is difficult to assess the limit of stable crack growth from Figure 10a, however a conservative estimate would put this point at roughly $15 \times 10^{4}$ cycles. Crack 


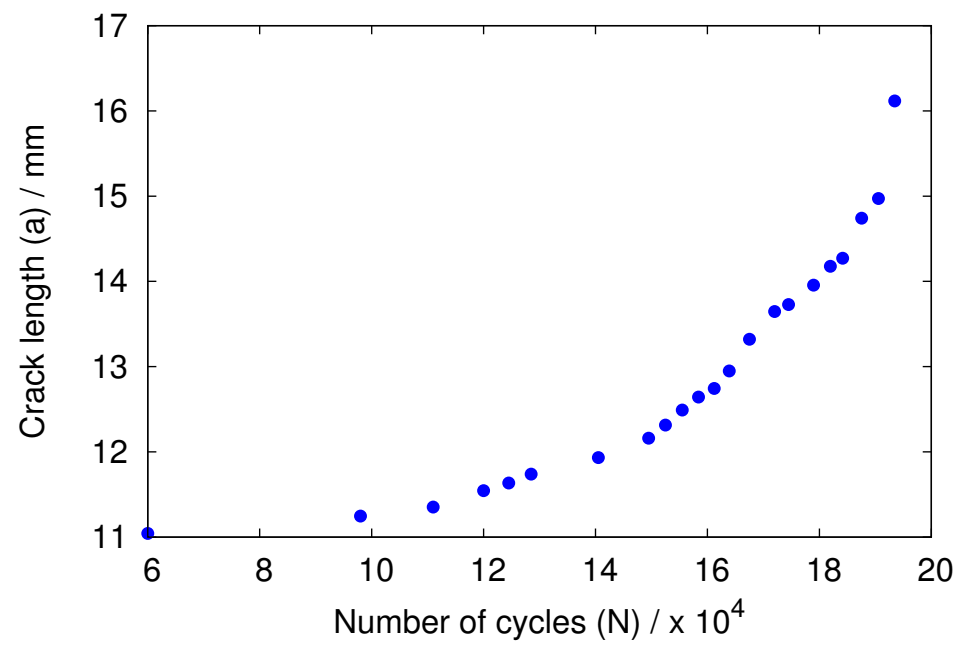

(a)

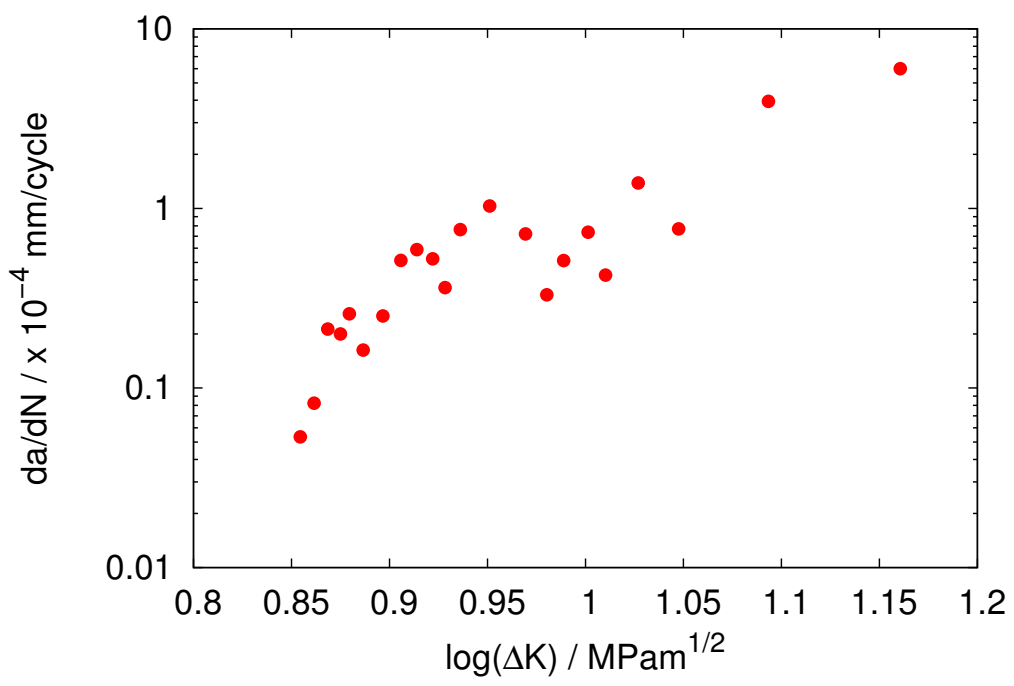

(b)

Figure 10: (a) Crack length as a function of fatigue cycles. (b) Fatigue crack growth rate as a function of $\Delta K$. 
growth rate under these stable conditions is $2.5 \times 10^{-5} \mathrm{~mm} /$ cycle. In Figure 10(b), the Paris law regime is represented by a linear region, which is not obviously distinguisable in this case due to significant scatter of the data. It lies approximately in the fairly narrow range $8 \mathrm{MPam}^{\frac{1}{2}}<\Delta K<11 \mathrm{MPa} \mathrm{m}^{\frac{1}{2}}$ $(0.9<\log (\Delta K)<1.05)$.

No results have previously been reported for fatigue crack growth rate, and further testing is recommended before any conclusion is made. 


\section{Conclusions}

A bainitic steel with a fine nanoscale structure was designed, and manufactured using clean steelmaking methods, for consideration as a potential aeroengine alloy. It was compared with two 'dirty' superbainitic alloys in order to assess whether the production method led to improved alloy performance.

The cleanliness of the experimental VIM/VAR processed alloy was studied, and although some manganese sulphide inclusions were identified, overall it conformed to the appropriate cleanliness standards required for use in the aeroengine industry.

The transformed alloy exhibited an impressivly high strength, with some impact toughness. It was found that both strength and Charpy impact toughness could be further improved by reducing the austenitisation temperature and thus the austenite grain size. Using this approach, an ultimate tensile strength of $2.5 \mathrm{GPa}$ and Charpy impact energy of $5 \mathrm{~J}$ were obtained. Although the impact energy is considered poor for steel in general, it was noted that this is common for results high strength steels. A fracture tough-

ness of $31 \mathrm{MPam}^{\frac{1}{2}}$ was measured in the alloy at the higher austenitisation temperature. 
The tempering resistance of the clean alloy was found to be superb, with limited reductions in tensile strength up to $600^{\circ} \mathrm{C}$ and hardness up to $500^{\circ} \mathrm{C}$. This observation is in line with previous work and thought to be a result of interphase carbide precipitation limiting the coarsening of the nanostructure. A decrease in fracture toughness was also observed following tempering, as tough retained austenite is replaced by brittle carbides and ferrite.

Various fatigue test results have been reported, including fatigue crack growth rate and low-cycle fatigue at elevated temperature. Low-cycle fatigue testing revealed that superior fatigue properties can be achieved when testing at elevated temperature. 


\section{References}

[1] F. G. Caballero, H. K. D. H. Bhadeshia, K. J. A. Mawella, D. G. Jones, and P. Brown. Very strong low temperature bainite. Materials Science and Technology, 18:279-284, 2002.

[2] C. Garcia-Mateo, F. G. Caballero, and H. K. D. H. Bhadeshia. Development of hard bainite. ISIJ International, 43:1238-1243, 2003.

[3] F. G. Caballero and H. K. D. H. Bhadeshia. Very strong bainite. Current Opinion in Solid State and Materials Science, 8:251-257, 2004.

[4] C. Garcia-Mateo, F. G. Caballero, and H. K. D. H. Bhadeshia. Mechanical properties of low-temperature bainite. Materials Science Forum, 500-501:495-502, 2005.

[5] C. Garcia-Mateo and F. G. Caballero. Ultra-high-strength bainitic steels. ISIJ International, 45:1736-1740, 2005.

[6] H. K. D. H. Bhadeshia. Nanostructured bainite. Proceedings of the Royal Society A, 466:3-18, 2010.

[7] C. Garcia-Mateo, F. G. Caballero, and H. K. D. H. Bhadeshia. Low temperature bainite. Journal de Physique IV, 112:285-288, 2003.

[8] C. Garcia-Mateo, F. G. Caballero, and H. K. D. H. Bhadeshia. Acceleration of low-temperature bainite. ISIJ International, 43:1821-1825, 2003. 
[9] C. García de Andrés, F. G. Caballero, C. Capdevila, and D. San Martín. Revealing austenite grain boundaries by thermal etching: advantages and disadvantages. Materials Characterization, 49:121-127, 2002.

[10] R. T. DeHoff. Quantitative microstructural analysis. In Fifty Years of Progress in Metallographic Techniques, pages 63-95, Philadelphia, 1968. ASTM, Americal Society for Testing and Materials.

[11] American Society for Testing and Materials. Standard test method for plane-strain fracture toughness of metallic materials. ASTM E399-90, 1997.

[12] M. J. Peet. Transformation and tempering of low-temperature bainite. $\mathrm{PhD}$ thesis, University of Cambridge, 2010.

[13] V. T. T. Miihkinen and D. V. Edmonds. Fracture toughness of two experimental high-strength bainitic low-alloy silicon containing steels. Materials Science and Technology, 3:441-449, 1987.

[14] L. C. D. Fielding. Understanding toughness and ductility in novel steels with mixed microstructures. PhD thesis, University of Cambridge, 2014.

[15] A. Matsuzaki and H. K. D. H. Bhadeshia. Effect of austenite grain size and bainite morphology on overall kinetics of bainite transformation in steels. Materials Science and Technology, 518:518-522, 1999.

[16] G. Xu, F. Liu, L. Wang, and H. Hu. A new approach to quantita- 
tive analysis of bainitic transformation in a superbainite steel. Scripta Materialia, 68:833-836, 2013.

[17] F. Hu, P. D. Hodgson, and K. M. Wu. Acceleration of the super bainite transformation through a coarse austenite grain size. Materials Letters, 122:240-243, 2014.

[18] B. Avishan, S. Yazdani, and S.H. Nedjad. Toughness variations in nanostructured bainitic steels. Materials Science and Engineering A, 548:106$111,2012$.

[19] M. Peet, P. Hill, M. Rawson, S. Wood, and H.K.D.H. Bhadeshia. Fatigue of extremly fine bainite. Materials Science and Technology, 27(1):119$123,2011$.

[20] C. Garcia-Mateo, M. Peet, F. G. Caballero, and H. K. D. H. Bhadeshia. Tempering of a hard mixture of bainitic ferrite and austenite. Materials Science and Technology, 20:814-818, 2004.

[21] H. S. Hasan, M. J. Peet, and H. K. D. H. Bhadeshia. Severe tempering of bainite generated at low transformation temperatures. International Journal of Materials Research, 103, 2012.

[22] C. N. Hulme-Smith, I. Lonardelli, M. J. Peet, A. C. Dippel, and H. K. D. H. Bhadeshia. Enhanced thermal stability in nanostructured bainitic steel. Scripta Materialia, 69:191-194, 2013. 
[23] H. S. Hasan, M. J. Peet, M-N. Avettand-Fenoel, and H. K. D. H. Bhadeshia. Effect of tempering upon the tensile properties of a nanostructured bainite steel. Materials Science and Engineering A, 615:340$347,2014$.

[24] A. Saha Podder. Tempering of a mixture of bainite and retained austenite. PhD thesis, University of Cambridge, 2011.

[25] A. Saha Podder and H. K. D. H. Bhadeshia. Thermal stability of austenite retained in bainitic steels. Materials Science and Engineering, 527:2121-2128, 2010. 